\title{
Green tea catechins for well-being and therapy: prospects and opportunities
}

This article was published in the following Dove Press journal:

Botanics: Targets and Therapy

9 December 2015

Number of times this article has been viewed

\section{Noriyuki Miyoshi' \\ Monira Pervin' \\ Takuji Suzuki ${ }^{2}$ \\ Keiko Unno ${ }^{3}$ \\ Mamoru Isemura' \\ Yoriyuki Nakamura'}

'School of Food and Nutritional Sciences, University of Shizuoka, Yada, Shizuoka, Japan; ${ }^{2}$ Faculty of Education, Art and Science, Yamagata University, Yamagata, Japan; ${ }^{3} \mathrm{School}$ of Pharmaceutical Sciences, University of Shizuoka, Yada, Shizuoka, Japan

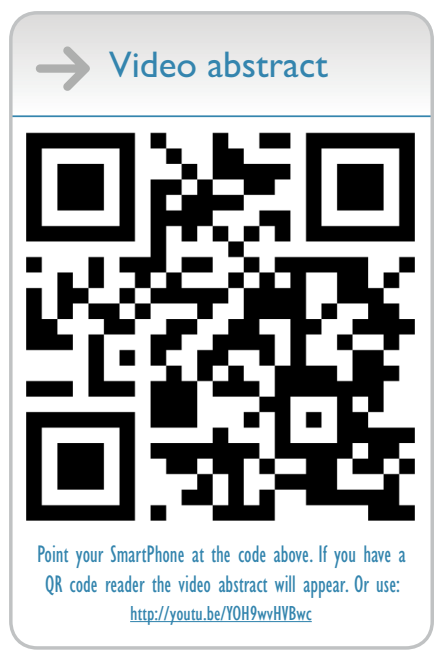

Correspondence: Mamoru Isemura School of Food and Nutritional Sciences, University of Shizuoka, Yada,

Shizuoka 422-8526, Japan

Tel +81542645822

Fax +81542645822

Email isemura@u-shizuoka-ken.ac.jp
Abstract: Tea is derived from the leaves and buds of Camellia sinensis (Theaceae) plant, and is consumed worldwide. Green tea was discovered in the People's Republic of China approximately 3,000 BC. Lu Yu (733-803) published a book that describes the history of tea, the techniques, and utensils used for manufacturing, the method of preparation, and drinking of tea in the People's Republic of China. Green tea contains various components with specific healthpromoting effects and is believed to exert protective effects against diseases such as cancer, obesity, diabetes, hepatitis, and neurodegenerative diseases. Of the various tea components, the polyphenol catechins have been the subject of extensive investigation. Among the catechins, (-)-epigallocatechin gallate has the strongest bioactivity in most cases. Caffeine induces alertness, decreases the sensation of fatigue, and has a diuretic effect. Theanine and $\gamma$-aminobutyric acid can lower the blood pressure and regulate brain function. Vitamin $\mathrm{C}$ exhibits antiscorbutic activity, prevents cataracts, and may boost the immune system. Majority of the scientific evidence based on cellular and animal experiments as well as a number of human epidemiological and intervention studies indicate that green tea and (-)-epigallocatechin gallate have beneficial health effects against various diseases. However, conflicting results have also been reported. Since confounding factors could affect the results, future studies should be designed to eliminate such factors for better understanding of the benefits of green tea on human health. Genetic and environmental factors such as race, sex, age, and lifestyle may also influence the results of human studies. Although care should be taken to avoid the consumption of green tea and supplements with very high catechin content, recent findings suggest that habitual drinking of green tea promotes longevity.

Keywords: green tea, catechin, epigallocatechin gallate, EGCG, health promotion, epidemiology, clinical trials

\section{Green tea: background and history of use}

Tea, a product of the leaves and buds of Camellia sinensis (Theaceae) plant, is consumed worldwide. Tea can broadly be classified based on the production method as unfermented (green tea), half-fermented (oolong tea), fully fermented (black tea), or postfermented (pu-erh tea). Green tea was discovered in the People's Republic of China approximately 3,000 BC. In the Tang Dynasty era in the People's Republic of China, Lu Yu (733-803), who is generally acknowledged as the founder of tea culture, wrote a traditional book titled "The Classic of Tea" or "Tea Sutra". 1,2 This book discussed the history of tea, the techniques, and the utensils used for manufacturing, as well as the method of preparation and drinking of tea in the People's Republic of China. Green tea was first brought to Japan, more than 1,000 years ago, from the People's Republic of China as a form of medicine. In 1211, the Japanese Zen monk Eisai wrote of the beneficial effects of 
tea in his book "Kissa Youjouki" in which he stated, "Tea is a marvelous preventive medicine to maintain people's health and has an extraordinary power to prolong life".,2,3

Green tea contains various ingredients with specific healthpromoting effects. For example, tea polyphenol catechins (Figure 1) are believed to exert protective effects against diseases such as cancer, obesity, diabetes, arteriosclerosis, neurodegenerative diseases, and tooth decay. ${ }^{1,4-7}$ They may also have antibacterial, antiviral, and hepatoprotective effects. Among the catechins, epigallocatechin gallate (EGCG) demonstrates the strongest bioactivity. The content of EGCG in green tea is higher than those in black tea and oolong tea, which may explain the superiority of green tea in terms of health benefits. ${ }^{7}$ Caffeine induces awakening, decreases the sensation of fatigue, and has a diuretic effect. Theanine and $\gamma$-aminobutyric acid lower the blood pressure and regulate brain function. Vitamin $\mathrm{C}$ exhibits antiscorbutic activity, prevents cataracts, and possibly boosts the immune system. ${ }^{7}$

A large body of scientific evidence has revealed the mechanisms by which green tea and EGCG exert beneficial effects on human health. Majority of scientific evidence based on cellular and animal experiments indicate that green tea can exert beneficial health effects. However, the evidence relating to its effects in humans remains inconclusive.

In this review, we focus mainly on the bioactivity of catechins, in particular on EGCG, which demonstrates the highest activity in most cases. We have mainly focused on the beneficial health effects of green tea on selected diseases such as cancer and diabetes, for which we have conducted basic experiments.

\section{Isolation of green tea catechins: chemical and pharmacological properties \\ Chemical structures of catechins}

A typically brewed green tea beverage (eg, $2.5 \mathrm{~g}$ tea leaves in $250 \mathrm{~mL}$ of hot water) contains $240-320 \mathrm{mg}$ of catechins,

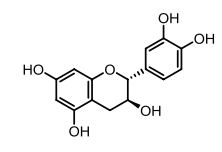

$(+)$-catechin

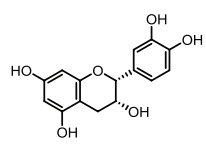

$(-)$-epicatechin

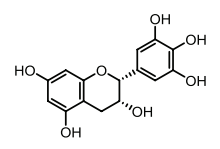

(-)-epigallocatechin

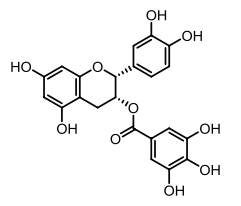

(-)-epicatechin gallate

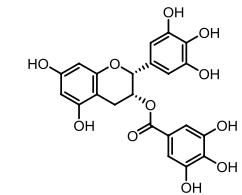

(-)-epigallocatechin gallate (EGCG)
Figure I Chemical structures of (+)-catechin and four major green tea catechins. of which $60 \%-65 \%$ is EGCG. ${ }^{1}$ Tsujimura reported the structures of epicatechin in 1929, epicatechin gallate in 1931, and epigallocatechin in 1934. ${ }^{3}$ In 1948, Bradfield and Penny successfully determined the structure of EGCG. ${ }^{3}$ It should be interesting to note that EGCG appears to be found only in the $C$. sinensis plant. ${ }^{8}$

\section{Biochemical properties of catechins}

Tea catechins are strong antioxidants and bind to proteins, lipids, nucleic acids, and metals. ${ }^{1}$ Experiments using EGCG immobilized on agarose have shown that EGCG binds to serum proteins such as fibronectin, fibrinogen, histidine-rich glycoproteins, and the cell surface protein, Fas. ${ }^{1,5}$ Recently, EGCG was shown to bind strongly to the $67 \mathrm{kDa}$ laminin receptor, ${ }^{8}$ B-cell lymphoma 2 (Bcl-2) proteins, vimentin, and peptidyl prolyl cis/trans isomerase. Accordingly, these proteins have been proposed to be the targets of EGCG and are considered as mediators of its anticancer activity. ${ }^{1,5}$ Thus, EGCG possibly exhibits multiple biological effects by binding to these biomolecules.

\section{Pharmacological properties of catechins}

It was demonstrated that 60 minutes after a single oral administration of EGCG in rats $(500 \mathrm{mg} / \mathrm{kg}$ body weight), the EGCG levels were $12.3 \mu \mathrm{M}$ in the plasma, $48.4 \mathrm{nmol} / \mathrm{g}$ in the liver, $0.5 \mathrm{nmol} / \mathrm{g}$ in the brain, $565 \mathrm{nmol} / \mathrm{g}$ in the small intestinal mucosa, and $68.6 \mathrm{nmol} / \mathrm{g}$ in the colon mucosa. ${ }^{9}$

Volunteers who ingested $1.5 \mathrm{~g}$ of decaffeinated green tea extract (GTE) containing $73 \mathrm{mg}$ EGCG, $68 \mathrm{mg}$ epigallocatechin, $22 \mathrm{mg}$ epicatechin gallate, and $25 \mathrm{mg}$ epicatechin per g, demonstrated peak plasma catechin levels within 1.5-2.5 hours, and the average peak plasma concentration of EGCG, epigallocatechin, and epicatechin was $0.71,1.8$, and $0.65 \mu \mathrm{M}$, respectively. ${ }^{10}$ When the dosage was increased from 1.5 to $3.0 \mathrm{~g}$, these values increased 2.7 - to 3.4 -fold.

Catechins can be degraded by microorganisms (in the intestinal tract) into various ring fission metabolites that can be found in human urine and plasma samples several hours after the ingestion of green tea. ${ }^{1}$

\section{Cell-based and animal experiments to determine the health benefits of catechins}

\section{Cancer}

Most cell- and animal-based experiments have demonstrated the anticancer effects of green tea and EGCG., 1,48 The major compound contributing to the anticancer effect of green tea is believed to be EGCG. The predominantly 
proposed mechanism for the anticancer activity of the leading candidates is apoptosis. Apoptosis is a programmed physiological cell death mechanism to eliminate unnecessary cells. The induction of apoptosis in cancer cells inhibits the development of cancer. Therefore, several anticancer drugs induce apoptosis in cancer cells. ${ }^{5}$

Hibasami et $\mathrm{al}^{11}$ were the first to demonstrate that catechins induced apoptosis in cancer cells. It was shown that green tea catechins significantly inhibited cancer development, increased survival rates, and induced apoptosis in an animal model that spontaneously develops metastatic prostate cancer. $^{12}$

EGCG has been shown to induce apoptosis by binding to Fas in cultured human leukemia cells. ${ }^{5}$ This binding activates the caspase 8 protease, which in turn activates a caspasedependent deoxyribonuclease that degrades DNA, thereby leading to cell death. Tachibana ${ }^{8}$ reported that the $67 \mathrm{kDa}$ laminin receptor was involved in EGCG-induced apoptosis. EGCG has a stronger apoptosis-inducing effect on cancer cells than that on normal cells. ${ }^{5,7}$

The involvement of micro RNAs (miRNAs) in EGCGinduced apoptosis has recently been proposed. miRNAs are single-stranded RNAs of 20-25 nucleotides. EGCG was found to induce apoptosis in hepatoma cells by upregulating miR-16, which led to the downregulation of the antiapoptotic protein Bcl-2. ${ }^{13}$ Epigenetic regulation by EGCG may be involved in various mechanisms, including apoptosis, which has been comprehensively reviewed by Pan et al. ${ }^{14}$

There are several other mechanisms by which catechins and other tea components exhibit anticancer activity. These include antioxidative effects, inhibition of cell cycle progression, inhibition of nuclear factor $\kappa \mathrm{B}$, activation of the mitogen-activated protein kinase cascade, and epigenetic modifications. ${ }^{4,5,7,14}$

EGCG-enriched catechins and green tea infusion have been shown to inhibit metastasis possibly by inhibiting the metalloproteinase activity. ${ }^{5}$ It was shown that oral administration of green tea catechins resulted in almost complete inhibition of distant site metastases of prostate cancer cells. ${ }^{12}$

\section{Diabetes}

Studies using cultured cells and laboratory animals have demonstrated the antidiabetic activity of green tea and catechins. They exert antidiabetic activity by inhibiting the $\alpha$-amylase and $\alpha$-glucosidase activity, inhibiting glucose absorption in the small intestine, protecting the pancreatic $\beta$ cells, improving insulin sensitivity of peripheral organs, and inhibiting gluconeogenesis (ie, glucose production from noncarbohydrates such as amino acids in the liver). ${ }^{15}$

Because $\alpha$-amylase and $\alpha$-glucosidase are necessary to produce glucose from dietary carbohydrates such as starch, inhibition of these enzymes contributes to the prevention and suppression of diabetes by impeding the rise in blood sugar levels. ${ }^{15}$ Similarly, the inhibition of glucose absorption in the small intestine also suppresses the increase in blood sugar levels. ${ }^{15}$

Improvements in insulin sensitivity result in the rapid suppression of blood glucose levels (which increase after meals) by promoting glucose uptake by peripheral tissues. When ingredients from green tea were added to cultured fat cells, they exhibited insulin-like activity in terms of the increase in glucose uptake. ${ }^{7}$ EGCG is the major ingredient exhibiting this activity in green tea.

Insulin-secreting pancreatic $\beta$ cells can be injured by diabetes-associated factors, and EGCG is known to protect against this cellular damage. ${ }^{7,15}$ The daily intake of green tea possibly exerts a protective effect against diabetes. This was demonstrated by the observed suppression of the rise of blood sugar levels in diabetic rats with drug-destroyed pancreatic $\beta$ cells receiving EGCG for 8 weeks, compared to that of the control rats. ${ }^{15}$

An increasing number of reports describe inhibitory effects of EGCG on gluconeogenesis. In cultured hepatocytes and hepatoma cells, EGCG demonstrated insulin-like activity by suppressing the gene expression of certain enzymes such as gluconeogenic enzymes, glucose-6-phosphatase, and phosphoenolpyruvate carboxykinase ${ }^{16,17}$ (Figure 2).

Animal experiments demonstrated similar results. ${ }^{5,15}$ One possible mechanism is that tea catechins, including EGCG, may suppress the expression of the transcription factor, hepatocyte nuclear factor $4 \alpha^{18}$ (Figure 2), which in turn leads to decreased expression of these gluconeogenic enzymes and reduced enzymatic activity, resulting in diminished glucose production. ${ }^{16,18}$

\section{Metabolic syndrome and related diseases}

Previous studies have shown that green tea and tea catechins have antiobesity properties. ${ }^{4,5}$ Tea catechins can reduce body fat by preferentially enhancing the utilization of fat as an energy source. This was demonstrated in animal experiments, which revealed that catechin diet enhanced hepatic gene expression of enzymes involved in $\beta$-oxidation. ${ }^{19}$

Tea catechins inhibit cell growth by suppressing lipogenesis in human MCF-7 breast cancer cells by downregulating fatty acid synthase (Fasn) gene expression and stimulating 


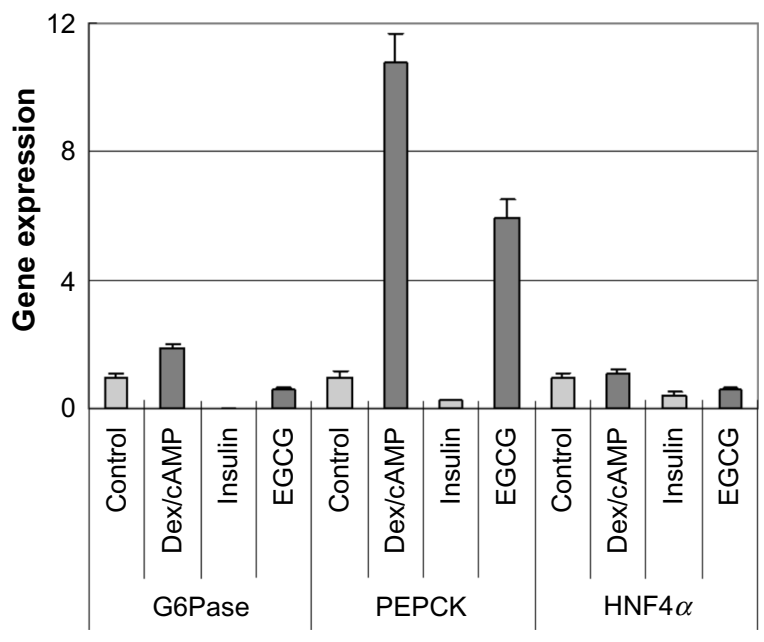

Figure 2 Effects of EGCG on gene expression of G6Pase, PEPCK, and HNF4 $\alpha .^{18}$ Notes: Gene expression is expressed as a relative value to that of control as 1.0 with a standard deviation. EGCG and insulin suppressed the elevated levels induced by the treatment with Dex/cAMP in rat hepatoma H4IIE cells. EGCG and insulin also inhibited the gene expression of HNF4 $\alpha$. Copyright (c) 2010. Biomedical Research Press. Reproduced from Yasui K, Tanabe H, Okada N, Fukutomi R, Ishigami Y, Isemura $M$. Effects of catechin-rich green tea on gene expression of gluconeogenic enzymes in rat hepatoma H4IIE cells. Biomed Res. 20I0;3I(3): I83-189.18

Abbreviations: Dex, dexamethasone; cAMP, cyclic adenosine monophosphate; EGCG, (-)-epigallocatechin gallate; G6Pase, glucose-6-phosphatase; HNF4 $\alpha$, hepatocyte nuclear factor $4 \alpha$; PEPCK, phosphoenolpyruvate carboxykinase.

cell energy expenditure in the mitochondria. ${ }^{20}$ It has been postulated based on experimental findings that downregulation of EGFR/PI3K/Akt/Sp-1 signaling pathways could be the underlying molecular mechanism for Fasn gene suppression by tea polyphenols. Moreover, administration of green tea leaves significantly decreased hepatic Fasn mRNA and protein levels in an animal study. ${ }^{21}$

A catechin-free fraction of green tea was also shown to reduce the hepatic gene expression of lipogenic enzymes, including Fasn, in mice. ${ }^{5}$ This fraction also reduced the gene expression of sterol regulatory element-binding transcription factor (Srebf)1 and Srebf2, which suggests that the reduction in the activity of these transcription factors contributes to the downregulation of lipogenic enzymes. ${ }^{5}$ These findings indicate that, in addition to EGCG, green tea contains previously unknown components that can prevent obesity and arteriosclerosis.

In addition, several studies suggested that inhibition of pancreatic lipase possibly plays a role in the antiobesity effect of tea components. For example, EGCG was shown to inhibit pancreatic lipase in a noncompetitive manner with respect to the substrate concentration. ${ }^{22}$ Epicatechin gallate also exhibited a similar inhibitory activity. ${ }^{23}$

\section{Liver diseases}

In a galactosamine-induced hepatitis model, rats that consumed a green tea beverage showed reduced hepatic gene and blood protein expression of proinflammatory cytokines such as tumor necrosis factor- $\alpha$ and interleukin-1 $\beta^{5,24}$ (Table 1). Consistent with this finding, histochemical observations revealed that the degree of hepatic injury was suppressed by green tea in the galactosamine-treated group. ${ }^{24}$ Suppression of these factors may also be involved in the mechanism by which green tea and catechins exhibit their preventive effect on other diseases including cancer and neurodegenerative diseases.

In a similar experiment in which the chronic effects of green tea were examined, green tea effectively prevented the progression of hepatitis to liver fibrosis. Ingestion of green tea reduced the gene expression of fibrosis-promoting factors, collagen, and transforming growth factor- $\beta .{ }^{5}$

Several other animal studies also demonstrated that green tea and EGCG were effective in preventing hepatitis induced by various drugs. ${ }^{25}$ EGCG has very strong antioxidant activity; therefore, it is possible that the hepatitis-preventive and relieving actions of catechins are the result of such strong antioxidant activity. ${ }^{26}$ Thus, green tea intake is expected to prevent the development of hepatitis and cirrhosis.

\section{Neurodegenerative diseases}

The accumulation of amyloid- $\beta$ and $\tau$ protein aggregates is a pathological hallmark of Alzheimer's disease. ${ }^{27,28}$ EGCG has been shown to reduce the aggregation of $A \beta$ proteins in an Alzheimer's disease mouse model. EGCG suppressed the production of amyloid- $\beta$ proteins by activating the $\alpha$-secretase pathway, leading to the normal metabolism of the amyloid precursor protein..$^{29}$ EGCG also prevented the aggregation of $\tau$ proteins into toxic oligomers. ${ }^{28}$

A number of studies on EGCG demonstrated its beneficial effects on cognition and memory. In a streptozotocin-induced model of dementia, it was shown that cognitive deficit, S100B

Table I Effects of green tea intake on hepatic mRNA expression and serum protein levels of inflammatory cytokines ${ }^{24}$

\begin{tabular}{|c|c|c|c|c|}
\hline \multirow[t]{2}{*}{ Group } & \multicolumn{2}{|c|}{ mRNA (\% of control) } & \multicolumn{2}{|c|}{ Protein $(\mathrm{ng} / \mathrm{mL})$} \\
\hline & TNF- $\alpha$ & IL-I $\beta$ & TNF- $\alpha$ & IL-I $\beta$ \\
\hline I (control) & $100 \pm 28$ & $100 \pm 16$ & $<0.7$ & $<0.7$ \\
\hline II & $603 \pm 102^{a}$ & $28 I \pm 46^{a}$ & $23.7 \pm 5.5^{b}$ & $68.3 \pm 5.9^{b}$ \\
\hline III & $366 \pm 112$ & $|7| \pm 26$ & $13.0 \pm 1.7^{\mathrm{b}}$ & $30.3 \pm 8.3^{b}$ \\
\hline IV & $166 \pm 67$ & $89 \pm 8$ & $<0.7$ & $<0.7$ \\
\hline
\end{tabular}

Notes: Hepatitis was induced in rats by peritoneal injection of galactosamine in groups II and III. Rats groups III and IV received the catechin-rich green tea beverage, while groups I and II received water. aSignificantly different from other groups at $P<0.05$; 'significantly different between groups II and III at $P<0.05$. Copyright (C) 2005. Biomedical Research Press. Reproduced from Abe K, ljiri M, Suzuki T, Taguchi K, Koyama Y, Isemura M. Green tea with a high catechin content suppresses inflammatory cytokine expression in the galactosamine-injured rat liver. Biomed Res. 2005;26(5): 187-192. ${ }^{24}$

Abbreviations: mRNA, messenger RNA; TNF- $\alpha$, tumor necrosis factor- $\alpha$; IL-I $\beta$, interleukin-I $\beta$. 
protein content and secretion, acetylcholine esterase activity, glutathione peroxidase activity, nitric oxide metabolites, and reactive oxygen species production were completely reversed by the administration of EGCG. ${ }^{30}$ EGCG rescued cognitive deficits in Down syndrome mouse models. ${ }^{31}$

The high prevalence of dementia in aged individuals suggests that aging is the most important risk factor and that senescence further enhances dementia. SAMP10, a mouse model of age-related neurodegeneration is suitable for studying brain senescence because brain atrophy and cognitive dysfunction are observed with aging. Also, reactive oxygen species production and oxidative damage are high in the brains of aged SAMP10 mice. In this model, catechins were found to prevent brain atrophy and cognitive dysfunction ${ }^{32}$ (Figure 3 ). In addition, psychosocially and chronically stressed mice exhibited a shorter life span and accelerated cognitive dysfunction. These deficiencies were prevented by ingestion of theanine. ${ }^{33}$

\section{Evidence from epidemiological studies \\ Cancer}

Epidemiological studies demonstrated that green tea and tea catechins exert preventive effects against various cancers. However, other studies failed to demonstrate such effects. Of the 127 case-control studies and 90 cohort studies published between 1965 and 2008, 51 case-control and 19 cohort studies showed an inverse association between green/black tea consumption and the risk for various types of cancer, including colon, lung, stomach, breast, prostate, ovarian, pancreatic, kidney, and bladder cancers. ${ }^{4}$

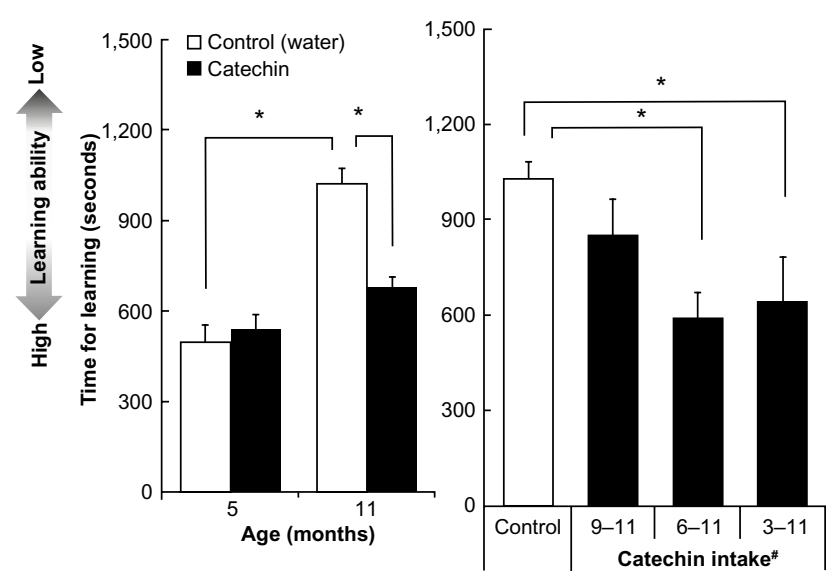

Figure 3 Effect of green tea catechins on learning ability in SAMPIO mice. Notes: The time needed for acquisition of the avoidance response was measured in mice that had consumed green tea catechins (hatched column) and in control mice (open column). "Three experimental groups consumed catechins during 9 to II months, 6 to 11 months, and 3 to II months of age. Each value represents a mean \pm SEM. $(* P<0.05)$. Reproduced with permission from Yakugaku Zasshi. Volume 135 Nol. (C) 2015 The Pharmaceutical Society of Japan. ${ }^{32}$

Abbreviation: SEM, standard error of mean.
More recent results were discussed comprehensively by Yuan ${ }^{6}$ and the selected ones are shown in Table 2.

In addition, several studies on other types of cancer have been reported. A 9-year follow-up study with 41,761 Japanese adults aged 40-79 years showed that green tea intake of $\geq 5$ cups/d reduced the risk of hematological malignancies. ${ }^{34}$ A significant inverse association between green tea consumption and the risk of endometrial endometrioid adenocarcinoma has also been reported. ${ }^{35}$

A case-control study found that green tea intake ( $\geq 500 \mathrm{~mL} / \mathrm{d}$ ) was associated with a decreased risk of clear cell renal cell carcinoma. ${ }^{36}$ In a large-scale, population-based case-control study in urban Shanghai, it was demonstrated that regular green tea consumption was associated with a reduction in the risk for pancreatic cancer in women. ${ }^{37}$ Drinking low-temperature green tea led to reduced risk of this cancer in both men and women, suggesting that the temperature of the tea is an important factor for such an effect. ${ }^{37}$ The results of a prospective cohort study with 100,507 individuals aged 40-69 years indicated that high green tea consumption may be positively associated with premenopausal thyroid cancer risk, but inversely associated with postmenopausal thyroid cancer risk. ${ }^{38}$

\section{Diabetes}

Several epidemiological studies have described the antidiabetic effects of green tea. Iso et $\mathrm{al}^{39}$ conducted a large cohort study and found that consumption of green tea, coffee, and total caffeine was associated with reduced risk of type 2 diabetes. The results of a case-control study conducted in the People's Republic of China with 4,800 subjects indicated that the consumption of green tea possibly protects against the development of type 2 diabetes, particularly in those who drink 16-30 cups/wk. ${ }^{40}$

A meta-analysis performed on 12 eligible studies found that daily tea consumption ( $\geq 3$ cups/d) was associated with a lower risk of type 2 diabetes, with a relative risk of 0.84 compared with that of the lowest consumption and non-tea-drinking groups. ${ }^{41}$ A study on beverage consumption in 25,639 adults in the UK found that the consumption of sugar-sweetened beverages was associated with high risk of type 2 diabetes, independent of adiposity. ${ }^{42}$ The study suggested that water or unsweetened tea/ coffee appear to be suitable alternatives to prevent diabetes.

However, several studies failed to identify a correlation between diabetes risk reduction and green tea consumption. For example, Pham et $\mathrm{al}^{43}$ identified a positive association between green tea consumption and insulin resistance in a study on 1,151 men and 289 women aged 18-69 years. Further studies are required to definitively determine the effects of 
Table 2 Epidemiological studies on the association of green tea and the risk of human cancera

\begin{tabular}{|c|c|c|}
\hline Cancer site & Study type/conditions & Outcomes \\
\hline Breast & $\begin{array}{l}\text { Meta-analysis of three CCS, with 5,062 cases } \\
\text { and } 5,483 \text { controls } \\
\text { Meta-analysis of five PCS, with 5,062 cases and } \\
5,483 \text { controls }\end{array}$ & $\begin{array}{l}70 \% \text { risk reduction in the highest consumption compared } \\
\text { with the no/low consumption } \\
\text { No risk reduction }\end{array}$ \\
\hline \multirow[t]{2}{*}{ Colorectum } & $\begin{array}{l}\text { PCS with } 8.9 \text { years of follow-up for }>60,000 \\
\text { Chinese individuals, aged } 45-74 \text { years } \\
\text { PCS with } 16 \text { years of follow-up for } 18,244 \text { men }\end{array}$ & $\begin{array}{l}\text { Nonsignificant risk increase in male consumers compared } \\
\text { with male nonconsumers } \\
60 \% \text { risk reduction in men with the highest urinary } \\
\text { levels compared with those with undetectable levels of } \\
\text { epigallocatechin }\end{array}$ \\
\hline & PCS with 46,023 men and 50,139 women & No risk reduction \\
\hline Esophagus & Review of I5 studies & $\begin{array}{l}\text { Significantly reduced risk (six studies), nonsignificant low risk } \\
\text { reduction (four studies), significantly increased risk (three } \\
\text { studies), and null association (two studies) }\end{array}$ \\
\hline \multirow[t]{2}{*}{ Liver } & $\begin{array}{l}\text { PCS with } 12.8 \text { years follow-up for } 60,076 \text { men } \\
\text { and } 29,713 \text { women, aged } 25-69 \text { years }\end{array}$ & $\begin{array}{l}9 \% \text { and } 49 \% \text { risk reduction in male and female tea consumers } \\
\text { (at least four times a week), respectively, compared with } \\
\text { other consumers }\end{array}$ \\
\hline & $\begin{array}{l}\text { PCS with }>9 \text { years follow-up for } 41,761 \text { Japanese } \\
\text { individuals aged } 40-79 \text { years }\end{array}$ & $\begin{array}{l}42 \% \text { risk reduction in consumers of } \geq 5 \text { cups } / d \text { compared } \\
\text { with those of }<1 \text { cup } / d\end{array}$ \\
\hline \multirow[t]{2}{*}{ Lung } & Review of 12 studies & $\begin{array}{l}\text { Significantly reduced risk (five studies), nonsignificant low } \\
\text { risk reduction (three studies), significantly increased risk } \\
\text { (one study), nonsignificantly increased risk (one study), and } \\
\text { null association (two studies) }\end{array}$ \\
\hline & Meta-analysis of 22 studies & $\begin{array}{l}22 \% \text { risk reductions in the highest consumers compared } \\
\text { with the lowest consumers }\end{array}$ \\
\hline Oral cavity & $\begin{array}{l}\text { PCS with I0.3 years follow-up for } 20,550 \text { men } \\
\text { and } 29,67 \text { I women aged } 40-79 \text { years }\end{array}$ & $\begin{array}{l}69 \% \text { risk reduction in female consumers of } \geq 5 \text { cups } / d \\
\text { compared with those of }<\mathrm{I} \text { cup } / \mathrm{d} \text {; no risk reduction in men }\end{array}$ \\
\hline Prostate & PCS with 49,920 men aged $40-69$ years & $\begin{array}{l}48 \% \text { risk reduction of advanced cancer in consumers of } \\
\geq 5 \mathrm{cups} / \mathrm{d} \text { compared with no/lowest consumers }\end{array}$ \\
\hline Stomach & $\begin{array}{l}\text { Pooled analysis of six PCS for the Japanese } \\
\text { population }\end{array}$ & $\begin{array}{l}21 \% \text { risk reduction in female consumers of } \geq 5 \text { cups } / d \\
\text { compared with those of }<\mathrm{I} \text { cup } / \mathrm{d} \text {; no risk reduction in men }\end{array}$ \\
\hline
\end{tabular}

Note: ${ }^{a}$ These data are selected from those discussed by Yuan. ${ }^{6}$

Abbreviations: CCS, case-control studies; PCS, prospective cohort studies.

green tea or GTE on insulin sensitivity and glycemic control in populations that are at a risk of developing type 2 diabetes.

\section{Metabolic syndrome and related diseases}

An improvement in body weight, body mass index (BMI), body fat, waist circumference, blood pressure, triglycerides, low-density lipoprotein cholesterol, high-density lipoprotein cholesterol, blood glucose concentration, and hemoglobin $\mathrm{A}_{1 \mathrm{c}}$ all prevent the development of metabolic syndrome. Only a few epidemiological studies have examined the beneficial effects of green tea consumption on metabolic syndrome or its components. In a cross-sectional study among Singaporean Chinese residents aged $\geq 40$ years, it was shown that drinking at least $150 \mathrm{~mL} /$ wk green tea was associated with a low risk of hypertension, with an odds ratio of $0.63 .{ }^{44}$ In contrast, several studies have found no association. For example, a cross-sectional study of 630 middle-aged Japanese men and 370 women found that green tea was not associated with serum lipid levels. ${ }^{45}$
A study on 1,902 Japanese men and women aged $\geq 40$ years demonstrated no correlation between green tea intake and metabolic syndrome, because green tea consumption did not influence blood pressure, abdominal circumference, fasting plasma glucose, or lipid indices. ${ }^{46}$ In addition, a Japanese cohort study of 554 adults in Tokushima, Japan, reported similar findings. ${ }^{47}$

\section{Liver diseases}

For liver cancer, several epidemiological studies showed preventive effects of green tea as previously discussed. In addition, some studies have investigated the impact of green tea on other liver diseases. A systematic review conducted in 2008 concluded that increased consumption of green tea may reduce the risk of liver disease. ${ }^{48}$ Imai and Nakachi ${ }^{49}$ conducted a study over a period of 4 years, from 1986 to 1990, on Japanese individuals aged $\geq 40$ years and demonstrated that intake of green tea was associated with a decrease in liver disease incidence in 1,371 men. 
Li et $\mathrm{a}^{50}$ suggested that ingestion of green tea is effective in preventing alcohol-induced hepatitis and infection with the hepatitis virus.

\section{Neurodegenerative diseases}

Several epidemiological studies have suggested that tea drinking may improve cognitive function. A meta-analysis covering eleven case-control and one cohort study concluded that tea consumption could protect against Parkinson's disease, especially in the Chinese populations. ${ }^{1} \mathrm{~A}$ recent metaanalysis also supported the conclusion that tea drinking can lower the risk of Parkinson's disease. ${ }^{1}$ Tea drinking was also associated with lowering the risk of depressive symptoms and psychological distress. ${ }^{1}$

Analysis of cross-sectional data from a study conducted in 2002 indicated that the odds ratio for the effect of green tea consumption at $\geq 2 \mathrm{cups} / \mathrm{d}$ on cognitive impairment was 0.46 compared to the consumption of 3 cups or less/wk. ${ }^{51}$ Similarly, a recent population-based prospective study of Japanese individuals aged $>60$ years found that the multipleadjusted odds ratio for the incidence of overall cognitive decline was 0.32 among individuals who consumed green tea every day and 0.47 among those who consumed green tea 1-6 d/wk, compared with the subjects who did not consume green tea. ${ }^{52}$

Several studies indicated that theanine relieved anxiety symptoms in patients with schizophrenic and schizoaffective disorders and that a combination of GTE and theanine improved memory and attention in subjects with mild cognitive impairments. ${ }^{1}$

\section{Confounding factors}

While a number of epidemiological studies provided evidence of reduced risk for diseases such as cancer, diabetes, and metabolic syndrome by drinking green tea, other studies have reported contrary effects. For example, Hou et $\mathrm{al}^{53}$ reviewed ten case-control studies and seven cohort studies published between 1988 and 2010 to examine the association between green tea consumption and reduced risk of stomach cancer. Their analysis showed that seven studies suggested no association, eight an inverse association, and one a positive association, indicating that currently there is insufficient information to conclusively support the inhibitory effects of green tea on stomach cancer. An example for a metabolic syndrome study is that of Takami et $\mathrm{al}^{47}$ who found that green tea consumption was not associated with the prevalence of metabolic syndrome or any of its components.
These inconsistent results may have resulted from several confounding factors, including the methods of quantifying tea consumption, tea temperature, cigarette smoking, and alcohol consumption. For example, among nonsmoking women, regular tea drinkers had a 35\% reduction in lung cancer risk compared with those who did not drink tea, but no association was found between green tea intake and lung cancer risk among smokers. ${ }^{6}$ Similarly, a recent study revealed an elevated risk of lung cancer in smokers. ${ }^{54}$

Gastrointestinal dysbiosis, an alteration of the gut bacteria, is associated with conditions such as cancer, metabolic syndrome, diabetes, and liver disease. Since green tea catechins can change intestinal microbiota, ${ }^{55}$ differential effects may result in different epidemiological outcomes. Genetic polymorphisms may also influence the effects of tea consumption on disease risk. ${ }^{1,6,54}$

\section{Evidence from clinical trials and prospects for therapy Cancer}

In a clinical experiment in which 42 patients were divided into four groups to receive either 500,750 , or $1,000 \mathrm{mg} / \mathrm{m}^{2}$ $\mathrm{GTE} / \mathrm{d}$ or placebo, the favorable response rates were $58 \%$ in patients who were given 750 or $1,000 \mathrm{mg} / \mathrm{m}^{2} \mathrm{GTE}$ and $36.4 \%$ in those who were given $500 \mathrm{mg} / \mathrm{m}^{2}$, but was only $18.2 \%$ in those assigned to the placebo arm. ${ }^{6}$ These results emphasize the benefit of GTE against the progression of precancerous lesions in the oral cavity toward malignant transformation.

In a study conducted in Italy, 30 men with high-grade prostate intraepithelial neoplasms were given $600 \mathrm{mg}$ of green tea catechins daily for 12 months. As a result, only one patient was found to have developed prostate cancer, compared with nine of the 30 patients in the placebo group. ${ }^{6}$ This chemopreventive effect was also demonstrated 2 years later. $^{6}$

In a clinical study in which 71 patients were administered $1.5 \mathrm{~g} \mathrm{GTE} / \mathrm{d}$ for 12 months with 65 control patients, the results of follow-up colonoscopy demonstrated that the incidence of metachronous adenomas was 31\% (20 of 65) in the control group and 15\% (nine of 60) in the GTE group. ${ }^{56}$ Thus, GTE appears useful for the chemoprevention of metachronous colorectal adenomas.

The standardized green tea polyphenol preparation Polyphenon $E^{\circledR}$ (Mitsui Norin Co, Ltd, Shizuoka, Japan) or sinecatechins has been subjected to several clinical trials ${ }^{57}$ and has been approved for the treatment of genital warts by the US Food and Drug Administration (FDA).${ }^{58}$ Randomized, double-blind, placebo-controlled trials have demonstrated 
the efficacy and safety of Polyphenon E 15\% ointment in the treatment of external anogenital warts. ${ }^{59}$ Protective effects of Polyphenon E on human cervical lesions have also been demonstrated. ${ }^{60}$ In another study, an oral 2,000 mg dose of Polyphenon E taken twice daily for up to 6 months was well tolerated by patients with chronic lymphocytic leukemia. ${ }^{61}$ Durable declines in the absolute lymphocyte count and/or lymphadenopathy were observed in majority of the patients. These results should incite future studies on the usefulness of green tea catechins as an anticancer agent.

\section{Diabetes}

A number of intervention studies have described the antidiabetic effect of green tea. A randomized controlled trial conducted on 53 male and 13 female type 2 diabetes patients in Shizuoka, Japan, showed that daily ingestion of GTE containing $544 \mathrm{mg}$ catechins for 2 months caused significant reductions in hemoglobin $A_{1 c}$ levels and diastolic blood pressure. However, no significant difference was observed in several other parameters. ${ }^{62}$ Similarly, a 2-month intervention study on 60 patients with mild hyperglycemia showed that the daily ingestion of GTE resulted in decreased levels of hemoglobin $\mathrm{A}_{1 \mathrm{c}}$, but not other biomarkers, such as fasting serum glucose level, after the cross-validation test. ${ }^{63}$

The results of an intervention study with Japanese type 2 diabetes patients showed that the increase in insulin was significantly greater in the catechin group than in the control group, although no apparent difference was noted between the two groups in blood levels of glucose and hemoglobin $\mathrm{A}_{1 \mathrm{c}} \cdot{ }^{64}$ In a randomized, double-blind, placebo-controlled trial performed with 92 Taiwanese individuals, the ingestion of $500 \mathrm{mg}$ GTE three times a day for 16 weeks, resulted in amelioration of the expression levels of an insulin-resistance marker and the secretion of glucagon-like peptide-1 in type 2 diabetes patients, suggesting favorable effects of GTE on diabetes. $^{65}$

Mozaffari-Khosravi et al ${ }^{66}$ conducted a randomized clinical trial in 100 mildly hypertensive patients with diabetes and showed that type 2 diabetic individuals who consumed three glasses of green tea daily for 4 weeks had significant decrease in systolic and diastolic blood pressure. Venables et $\mathrm{al}^{67}$ showed that the acute ingestion of GTE increased fat oxidation during moderate intensity exercise and improved insulin sensitivity and glucose tolerance in healthy young men. A double-blind randomized intervention study on nondiabetic overweight or obese male subjects in the UK found that twice daily ingestion of $400 \mathrm{mg}$ EGCG for 8 weeks resulted in reduced diastolic blood pressure. ${ }^{68}$ However, no significant effects on glucose tolerance, insulin sensitivity, and insulin secretion were observed. ${ }^{68}$

On the other hand, several intervention studies found no beneficial effects of green tea on diabetes. A double-blind, placebo-controlled, randomized multiple-dose $(0,350$, or $750 \mathrm{mg}$ catechins and theaflavins for 3 months) study conducted in the USA demonstrated no effects on the level of hemoglobin $\mathrm{A}_{1 \mathrm{c}}$ in patients with a medical history of diabetes of more than 6 months. ${ }^{69}$ A crossover randomized control trial without blinding on 14 healthy volunteers of 22-35 years of age in southern Sweden showed that there was no glucose or insulin-lowering effects after consumption of $300 \mathrm{~mL}$ of green tea or water. ${ }^{70} \mathrm{~A}$ meta-analysis of randomized controlled trials found that the consumption of green tea did not decrease the levels of fasting plasma glucose, fasting serum insulin, hemoglobin $\mathrm{A}_{1 \mathrm{c}}$, or the insulin resistance index in populations at risk of type 2 diabetes. ${ }^{71}$

Thus, clinical trials in humans on the effects of green tea have demonstrated conflicting results. This could be due to differences in genetic and environmental factors such as race, sex, age, and lifestyle, as well as differences in the ingredients, concentrations, drinking frequency, and drinking period of tea. Therefore, it is necessary to clarify the antidiabetic effects of green tea by taking these factors into account in future studies.

\section{Metabolic syndrome and related diseases}

A number of clinical intervention studies have shown the fat-suppressing effects of green tea and green tea catechins., ${ }^{4,5}$ Basu et $\mathrm{al}^{72}$ demonstrated in a study conducted in the USA that body weight and blood lipid oxidation index were decreased in patients with metabolic syndrome following consumption of green tea and green tea catechins for 8 weeks. In a study of 45 elderly patients with metabolic syndrome, 24 patients consuming three cups of green tea brewed from $1 \mathrm{~g}$ tea bags/d for 60 days showed a reduction in BMI and waist circumference. ${ }^{73}$ Nagao et $\mathrm{al}^{64}$ demonstrated that the continuous ingestion of green tea rich in catechins led to a reduction in body fat, systolic blood pressure, and lowdensity lipoprotein cholesterol. Tea catechins may reduce body fat by preferentially enhancing the utilization of fat as an energy source since animal studies revealed that the catechin diet enhanced hepatic gene expression of enzymes involved in $\beta$-oxidation. ${ }^{19}$

An intervention study of 195 male and female subjects aged 20-65 years with a high BMI indicative of obesity revealed that subjects with high catechin intake had lower body weight, BMI, abdominal circumference, total abdominal 
fat area, and visceral fat area values after 12 weeks than those of the placebo group.., 5

In contrast, a randomized, double-blind, placebocontrolled study with 83 obese premenopausal women demonstrated that dietary supplementation with $300 \mathrm{mg} / \mathrm{d}$ of EGCG for 12 weeks did not enhance energy-restricted diet-induced adiposity reductions, and did not improve weight-loss-induced changes in cardiometabolic risk factors. ${ }^{74}$

\section{Liver diseases}

A clinical trial was conducted on nine cases of intractable chronic hepatitis $\mathrm{C}$ with a very high viral load of more than $850 \mathrm{kIU} / \mathrm{mL}$, in which patients received a combination therapy regimen of $6 \mathrm{~g}$ of green tea powder/d and interferon/ ribavirin. The green tea therapy was 3.5 times more effective than treatment without green tea. ${ }^{7,75}$ These results warrant further study on the clinical use of green tea and GTE.

A randomized, placebo-controlled, Phase IIa clinical trial demonstrated a protective role of green tea catechins in liver damage induced by hepatitis B virus (HBV).${ }^{76}$ Individuals seropositive for the HBV antigen and aflatoxin-albumin adducts were randomly assigned to a $500 \mathrm{mg}$ catechins/d group, a 1,000 mg group, or a placebo group. After 3 months, these catechin groups showed significantly decreased urinary concentrations of 8-hydroxy-deoxyguanosine compared with that of the placebo group. These results suggest that green tea catechins are effective in reducing oxidative DNA damage, which could lead to hepatitis development and liver cancer in patients with $\mathrm{HBV}$ infection.

\section{Neurodegenerative diseases}

In a pilot study which included two men and ten women (mean age: 88 years), consumption of green tea powder at $2 \mathrm{~g} / \mathrm{d}$ for 3 months was shown to be effective in improving cognitive function or reducing the progression of cognitive dysfunction. ${ }^{77}$

The excessive burden of oxidative stress may be related to aging and neurodegenerative diseases, and green tea may improve this stress. ${ }^{1}$ Consumption of theanine induced higher frequencies of $\alpha$-waves as shown by electroencephalographic measurement. ${ }^{78} \gamma$-Aminobutyric acid was shown to affect the activity of the central nervous system during stress conditions induced by mental tasks. Oral intake of $\gamma$-aminobutyric acid diminished the stress-induced decrease in frequency of $\alpha$ - and $\beta$-band brain waves compared with the placebo. ${ }^{79}$

In addition, green tea intake may cause an increase of $\theta$-wave frequency, suggesting its role in cognitive function, specifically alertness and attention. ${ }^{80}$

\section{Confounding factors}

Several intervention studies have found beneficial effects of green tea and catechins on human diseases, but others have failed to find such effects. The inconsistency may be due to incomplete adjustments of confounding factors as described.

\section{Possible deleterious effects}

Mazzanti et $\mathrm{al}^{81}$ reported that consumption of a green tea supplement was associated with liver damage. Patel et a ${ }^{82}$ presented a case of acute impending liver failure in a male using a weight loss product containing GTE. The problems associated with EGCG-triggered hepatotoxicity have been discussed in detail. ${ }^{83}$ Therefore, the intake of green tea and supplements with very high catechin concentrations should be taken with caution or avoided.

In addition, Shirai et a ${ }^{84}$ reported that 21 cases of asthma that were attributable to green tea. Hypersensitivity pneumonitis was reported in a 51-year-old man who underwent tea catechin inhalation therapy for 1 month and tuberculosis treatment for 3.5 months. ${ }^{85}$

\section{Prospects and opportunities}

There are several possible beneficial health effects of green tea other than those described here, including effects on bone health, dental health, allergies, the common cold, and influenza. ${ }^{4,57}$ Future studies will provide a more detailed information on these issues.

Clinical trials on the catechin-based drug approved by FDA for cancer therapy as described are in progress, ${ }^{57}$ and the results may promote their use for diseases other than cancer.

Several limitations of green tea application in health promotion that include low bioavailability and low stability may be solved by ongoing and future studies. Development in drug delivery system may help to increase the bioavailability. Several basic studies have suggested that the effect of EGCG may be enhanced by other agents. For example, a combination of EGCG and nonsteroidal anti-inflammatory drug sulindac was proven to be useful in reducing the degree of azoxymethane-induced precancerous lesions in rat colon. ${ }^{5}$ Thus, future studies may discover the effective combination of green tea components and various chemicals. We may also expect the usefulness of chemical modifications of tea components. For example, acylated EGCG was shown to have a higher anticancer effect than EGCG. ${ }^{86}$

A recent large-scale epidemiological research study on 90,914 Japanese individuals between 1990 and 1994, with 18.7-year follow-up, found that green tea was inversely 
associated with mortality from heart disease in both men and women and mortality from cerebrovascular disease and respiratory disease in men. ${ }^{87}$ This study also revealed that the consumption of green tea reduced the risk of mortality from all causes. As previously mentioned, daily consumption of 2 cups/d or even 6 cups/wk of green tea appears to be effective for the prevention of cognitive defects. Therefore, it might be worthwhile to drink several cups of green tea every day for improved health and longevity.

\section{Conclusion}

Green tea contains various components with specific healthpromoting effects and is believed to have protective effects against diseases such as cancer, obesity, diabetes, hepatitis, and neurodegenerative diseases. Majority of scientific evidence based on cellular and animal experiments as well as a number of human epidemiological and intervention studies indicate that green tea and EGCG have beneficial health effects against various diseases. However, conflicting results have also been reported. Since confounding factors could affect the results, future studies should eliminate such factors to better understand the benefits of green tea for human health. Genetic and environmental factors such as race, sex, age, lifestyle, and intestinal microbiota may also influence the results observed in human studies. Although care should be taken not to ingest green tea and supplements with a very high catechin content, recent findings suggest that habitual drinking of green tea promotes longevity.

\section{Disclosure}

The authors report no conflicts of interest in this work.

\section{References}

1. Yang CS, Chen G, Wu Q. Recent scientific studies of a traditional Chinese medicine, tea, on prevention of chronic diseases. J Tradit Complement Med. 2014;4(1):17-23.

2. Nakamura Y. Characteristics of Japanese tea. In: Etoh H, Tomita I, Shinmura J, et al, editors. Scientific evidence for the health benefits of tea. Tokyo, Japan: Noubunkyou Production. 2015;14-24.

3. Nakagawa M. The History of Tea Components. Pretoria, South Africa: University Editor CC; 2015.

4. Yang CS, Wang X, Lu G, Picinich SC. Cancer prevention by tea: animal studies, molecular mechanisms and human relevance. Nat Rev Cancer. 2009;9(6):429-439.

5. Suzuki Y, Miyoshi N, Isemura M. Health-promoting effects of green tea. Proc Jpn Acad Ser B Phys Biol Sci. 2012;88(3):88-101.

6. Yuan JM. Cancer prevention by green tea: evidence from epidemiologic studies. Am J Clin Nutr. 2013;98(Suppl 6):1676-1681.

7. Suzuki T, Miyoshi N, Hayakawa S, Imai S, Isemura M, Nakamura Y. Health benefits of tea consumption. In: Ted Wilson T, Temple NJ, editors. Beverage Impacts on Health and Nutrition. 2nd ed. Cham, Switzerland: Springer International Publishing AG. In press, 2015.

8. Tachibana H. Green tea polyphenol sensing. Proc Jpn Acad Ser B Phys Biol Sci. 2011;87(3):66-80.
9. Nakagawa K, Miyazawa T. Absorption and distribution of tea catechin, (-)-epigallocatechin-3-gallate, in the rat. J Nutr Sci Vitaminol (Tokyo). 1997;43(6):679-684.

10. Chow HH, Hakim IA. Pharmacokinetic and chemoprevention studies on tea in humans. Pharmacol Res. 2011;64(2):105-112.

11. Hibasami H, Achiwa Y, Fujikawa T, Komiya T. Induction of programmed cell death (apoptosis) in human lymphoid leukemia cells by catechin compounds. Anticancer Res. 1996;16:1943-1946.

12. Gupta S, Hastak K, Ahmad N, Lewin JS, Mukhtar H. Inhibition of prostate carcinogenesis in TRAMP mice by oral infusion of green tea polyphenols. Proc Natl Acad Sci U S A. 2001;98(18):10350-10355.

13. Singh BN, Shankar S, Srivastava RK. Green tea catechin, epigallocatechin-3-gallate (EGCG): mechanisms, perspectives and clinical applications. Biochem Pharmacol. 2011;82(12):1807-1821.

14. Pan MH, Lai CS, Wu JC, Ho CT. Epigenetic and disease targets by polyphenols. Curr Pharm Des. 2013;19(34):6156-6185.

15. Miyoshi N. Anti-diabetic effects. In: Isemura M, editor. Health Benefits of Green Tea. 2013. Available from: http://dfns.u-shizuoka-ken.ac.jp/ labs/tsc/.

16. Waltner-Law ME, Wang XL, Law BK, Hall RK, Nawano M, Granner DK. Epigallocatechin gallate, a constituent of green tea, represses hepatic glucose production. J Biol Chem. 2002;277(38):34933-34940.

17. Collins QF, Liu HY, Pi J, Liu Z, Quon MJ, Cao W. Epigallocatechin-3gallate (EGCG), a green tea polyphenol, suppresses hepatic gluconeogenesis through $5^{\prime}$-AMP-activated protein kinase. J Biol Chem. 2007;282(41):30143-30149.

18. Yasui K, Tanabe H, Okada N, Fukutomi R, Ishigami Y, Isemura M. Effects of catechin-rich green tea on gene expression of gluconeogenic enzymes in rat hepatoma H4IIE cells. Biomed Res. 2010;31(3): 183-189.

19. Murase T, Nagasawa A, Suzuki J, Hase T, Tokimitsu I. Beneficial effects of tea catechins on diet-induced obesity: stimulation of lipid catabolism in the liver. Int J Obes Relat Metab Disord. 2002;26(11):1459-1464.

20. Lin JK, Lin-Shiau SY. Mechanisms of hypolipidemic and anti-obesity effects of tea and tea polyphenols. Mol Nutr Food Res. 2006;50(2): 211-217.

21. Huang HC, Lin JK. Pu-erh tea, green tea, and black tea suppresses hyperlipidemia, hyperleptinemia and fatty acid synthase through activating AMPK in rats fed a high-fructose diet. Food Funct. 2012;3(2):170-177.

22. Grove KA, Sae-tan S, Kennett MJ, Lambert JD. (-)-Epigallocatechin-3gallate inhibits pancreatic lipase and reduces body weight gain in high fat-fed obese mice. Obesity (Silver Spring). 2012;20(11):2311-2313.

23. Yuda N, Tanaka M, Suzuki M, Asano Y, Ochi H, Iwatsuki K. Polyphenols extracted from black tea (Camellia sinensis) residue by hot-compressed water and their inhibitory effect on pancreatic lipasein vitro. J Food Sci. 2012;77(12):254-261.

24. Abe K, Ijiri M, Suzuki T, Taguchi K, Koyama Y, Isemura M. Green tea with a high catechin content suppresses inflammatory cytokine expression in the galactosamine-injured rat liver. Biomed Res. 2005;26(5):187-192.

25. Suzuki T. Effects on hepatitis and liver fibrosis. In: Isemura M, editor. Health Benefits of Green Tea. 2013. Available from: http://dfns.ushizuoka-ken.ac.jp/labs/tsc/.

26. Relja B, Töttel E, Breig L, et al. Plant polyphenols attenuate hepatic injury after hemorrhage/resuscitation by inhibition of apoptosis, oxidative stress, and inflammation via NF-kappaB in rats. Eur J Nutr. 2012;51(3):311-321.

27. Selkoe DJ. Translating cell biology into therapeutic advances in Alzheimer's disease. Nature.1999;399(Supp1 6738):A23-A31.

28. Wobst HJ, Sharma A, Diamond MI, Wanker EE, Bieschke J. The green tea polyphenol (-)-epigallocatechin gallate prevents the aggregation of tau protein into toxic oligomers at substoichiometric ratios. FEBS Lett. 2015;589(1):77-83.

29. Rezai-Zadeh K, Shytle D, Sun N, et al. Green tea epigallocatechin-3gallate (EGCG) modulates amyloid precursor protein cleavage and reduces cerebral amyloidosis in Alzheimer transgenic mice. J Neurosci. 2005;25(38):8807-8814. 
30. Biasibetti R, Tramontina AC, CostaAP, etal. Green tea (-)epigallocatechin3-gallate reverses oxidative stress and reduces acetylcholinesterase activity in a streptozotocin-induced model of dementia. Behav Brain Res. 2013;236(1):186-193.

31. De la Torre R, De Sola S, Pons M, et al. Epigallocatechin-3-gallate, a DYRK1A inhibitor, rescues cognitive deficits in Down syndrome mouse models and in humans. Mol Nutr Food Res. 2014;58(2):278-288.

32. Unno K, Prevention of senescence and stress by food consumption. Yakugaku Zasshi. 2015;135(1):41-46.

33. Unno K, Iguchi K, Tanida N, et al. Ingestion of theanine, an amino acid in tea, suppresses psychosocial stress in mice. Exp Physiol. 2013;98(1):290-303.

34. Naganuma T, Kuriyama S, Kakizaki M, et al. Green tea consumption and hematologic malignancies in Japan: the Ohsaki study. Am J Epidemiol. 2009;170(6):730-738

35. Kakuta Y, Nakaya N, Nagase S, et al. Case-control study of green tea consumption and the risk of endometrial endometrioid adenocarcinoma. Cancer Causes Control. 2009;20(5):617-624.

36. Wang G, Hou J, Ma L, et al. Risk factor for clear cell renal cell carcinoma in Chinese population: a case-control study. Cancer Epidemiol. 2012;36(2):177-182.

37. Wang J, Zhang W, Sun L, et al. Green tea drinking and risk of pancreatic cancer: a large-scale, population-based case-control study in urban Shanghai. Cancer Epidemiol. 2012;36(6):e354-e358.

38. Michikawa T, Inoue M, Shimazu T, et al. Green tea and coffee consumption and its association with thyroid cancer risk: a population-based cohort study in Japan. Cancer Causes Control. 2011;22(7):985-993.

39. Iso H, Date C, Wakai K; for JACC Study Group. The relationship between green tea and total caffeine intake and risk for self-reported type 2 diabetes among Japanese adults. Ann Intern Med. 2006;144(8):554-562.

40. Huang H, Guo Q, Qiu C, et al. Associations of green tea and rock tea consumption with risk of impaired fasting glucose and impaired glucose tolerance in Chinese men and women. PLoS One. 2013; 8(11):e79214.

41. Yang J, Mao QX, Xu HX, Ma X, Zeng CY. Tea consumption and risk of type 2 diabetes mellitus: a systematic review and meta-analysis update. BMJ Open. 2014;4(7):e005632.

42. O'Connor L, Imamura F, Lentjes MA, Khaw KT, Wareham NJ, Forouhi NG. Prospective associations and population impact of sweet beverage intake and type 2 diabetes, and effects of substitutions with alternative beverages. Diabetologia. 2015;58(7):1474-1483.

43. Pham NM, Nanri A, Kochi T, et al. Coffee and green tea consumption is associated with insulin resistance in Japanese adults. Metabolism. 2014;63(3):400-408

44. Li W, Yang J, Zhu XS, Li SC, Ho PC. Correlation between tea consumption and prevalence of hypertension among Singaporean Chinese residents aged $\geq 40$ years. J Hum Hypertens. Epub 2015 May 28. doi: 10.1038/jhh.2015.45.

45. Tsubono Y, Tsugane S. Green tea intake in relation to serum lipid levels in middle-aged Japanese men and women. Ann Epidemiol. 1997;7(4):280-284.

46. Hino A, Adachi H, Enomoto M, et al. Habitual coffee but not green tea consumption is inversely associated with metabolic syndrome: an epidemiological study in a general Japanese population. Diabetes Res Clin Pract. 2007;76(3):383-389.

47. Takami H, Nakamoto M, Uemura $\mathrm{H}$, et al. Inverse correlation between coffee consumption and prevalence of metabolic syndrome: baseline survey of the Japan Multi-Institutional Collaborative Cohort (J-MICC) Study in Tokushima, Japan. J Epidemiol. 2013;23(1):12-20.

48. Jin $\mathrm{X}$, Zheng RH, Li YM. Green tea consumption and liver disease: a systematic review. Liver Int. 2008;28(7):990-996.

49. Imai K, Nakachi K. Cross sectional study of effects of drinking green tea on cardiovascular and liver diseases. BMJ. 1995;310(6981): 693-696.

50. Li Y, Chang SC, Goldstein BY, et al. Green tea consumption, inflammation and the risk of primary hepatocellular carcinoma in a Chinese population. Cancer Epidemiol. 2011;35(4):362-368.
51. Kuriyama S, Hozawa A, Ohmori K, et al. Green tea consumption and cognitive function: a cross-sectional study from the Tsurugaya Project 1 . Am J Clin Nutr. 2006;83(2):355-361.

52. Noguchi-Shinohara M, Yuki S, Dohmoto C, et al. Consumption of green tea, but not black tea or coffee, is associated with reduced risk of cognitive decline. PLoS One. 2014;9(5):e96013.

53. Hou IC, Amarnani S, Chong MT, Bishayee A. Green tea and the risk of gastric cancer: epidemiological evidence. World J Gastroenterol. 2013;19(24):3713-3722.

54. Lin IH, Ho ML, Chen HY, et al. Smoking, green tea consumption, genetic polymorphisms in the insulin-like growth factors and lung cancer risk. PLoS One. 2012;7(2):e30951.

55. Hara Y. Influence of tea catechins on the digestive tract. J Cell Biochem Suppl.1997;27:52-58.

56. Shimizu M, Fukutomi Y, Ninomiya M, et al. Green tea extracts for the prevention of metachronous colorectal adenomas: a pilot study. Cancer Epidemiol Biomarkers Prev. 2008;17(11):3020-3025.

57. Clinicaltrials.gov. Available from: http://clinicaltrials/gov/ with a keyword: Polyphenon E. Accessed September 28, 2015.

58. Hara Y. Tea catechins and their applications as supplements and pharmaceutics. Pharmacol Res. 2011;64(2):100-104.

59. Gross G, Meyer KG, Pres H, Thielert C, Tawfik H, Mescheder A. A randomized, double-blind, four-arm parallel-group, placebocontrolled Phase II/III study to investigate the clinical efficacy of two galenic formulations of Polyphenon $\mathrm{E}$ in the treatment of external genital warts. J Eur Acad Dermatol Venereol. 2007;21(10):1404-1412.

60. Ahn WS, Yoo J, Huh SW, et al. Protective effects of tea extracts (polyphenon E and EGCG) on human cervical lesiollls. Eur J Carlcer Prev. 2003;12(5):383-390.

61. Shanafelt TD, Call TG, Zent CS, et al. Phase 2 trial of daily, oral Polyphenon E in patients with asymptomatic, Rai stage 0 to II chronic lymphocytic leukemia. Cancer. 2013;119(2):363-370.

62. Fukino Y, Shimbo M, Aoki N, Okubo T, Iso H. Randomized controlled trial for an effect of green tea consumption on insulin resistance and inflammation markers. J Nutr Sci Vitaminol (Tokyo). 2005;51(5): 335-342.

63. Fukino Y, Ikeda A, Maruyama K, Aoki N, Okubo T, Iso H. Randomized controlled trial for an effect of green tea-extract powder supplementation on glucose abnormalities. Eur J Clin Nutr. 2008;62(8):953-960.

64. Nagao T, Meguro S, Hase T, et al. A catechin-rich beverage improves obesity and blood glucose control in patients with type 2 diabetes. Obesity (Silver Spring). 2009;17(2):310-317.

65. Liu CY, Huang CJ, Huang LH, Chen IJ, Chiu JP, Hsu CH. Effects of green tea extract on insulin resistance and glucagon-like peptide 1 in patients with type 2 diabetes and lipid abnormalities: a randomized, double-blinded, and placebo-controlled trial. PLoS One. 2014;9(3):e91163.

66. Mozaffari-Khosravi H, Ahadi Z, Barzegar K. The effect of green tea and sour tea on blood pressure of patients with type 2 diabetes: a randomized clinical trial. J Diet Suppl. 2013;10(2):105-115.

67. Venables MC, Hulston CJ, Cox HR, Jeukendrup AE. Green tea extract ingestion, fat oxidation, and glucose tolerance in healthy humans. $\mathrm{Am}$ J Clin Nutr. 2008;87(3):778-784.

68. Brown AL, Lane J, Coverly J, et al. Effects of dietary supplementation with the green tea polyphenol epigallocatechin-3-gallate on insulin resistance and associated metabolic risk factors: randomized controlled trial. Br J Nutr. 2009;101(6):886-894.

69. Mackenzie T, Leary L, Brooks WB. The effect of an extract of green and black tea on glucose control in adults with type 2 diabetes mellitus: double-blind randomized study. Metabolism. 2007;56(10): 1340-1344.

70. Josic J, Olsson AT, Wickeberg J, Lindstedt S, Hlebowicz J. Does green tea affect postprandial glucose, insulin and satiety in healthy subjects: a randomized controlled trial. Nutr J. 2010;9:63.

71. Wang X, Tian J, Jiang J, et al. Effects of green tea or green tea extract on insulin sensitivity and glycaemic control in populations at risk of type 2 diabetes mellitus: a systematic review and meta-analysis of randomised controlled trials. J Hum Nutr Diet. 2014;27(5):501-512. 
72. Basu A, Sanchez K, Leyva MJ, et al. Green tea supplementation affects body weight, lipids, and lipid peroxidation in obese subjects with metabolic syndrome. J Am Coll Nutr. 2010;29(1):31-40.

73. Vieira Senger AE, Schwanke CH, Gomes I, Valle Gottlieb MG. Effect of green tea (Camellia sinensis) consumption on the components of metabolic syndrome in elderly. J Nutr Health Aging. 2012;16(9): 738-742.

74. Mielgo-Ayuso J, Barrenechea L, Alcorta P, Larrarte E, Margareto J, Labayen I. Effects of dietary supplementation with epigallocatechin3-gallate on weight loss, energy homeostasis, cardiometabolic risk factors and liver function in obese women: randomised, double-blind, placebo-controlled clinical trial. Br J Nutr. 2014;111(7):1263-1271.

75. Sameshima Y, Ishida Y, Ono Y, Hujita M, Kuriki Y. Green tea powder enhances the safety and efficacy of interferon $\alpha-2 b$ plus ribavirin combination therapy in chronic hepatitis $\mathrm{C}$ patients with a very high genotype $1 \mathrm{HCV}$ load. In: Isemura M, editor. Beneficial Health Effect of Green Tea. Kerala, India: Research Signpost; 2008:113-119.

76. Luo H, Tang L, Tang M, et al. Phase IIa chemoprevention trial of green tea polyphenols in high-risk individuals of liver cancer: modulation of urinary excretion of green tea polyphenols and 8-hydroxydeoxyguanosine. Carcinogenesis. 2006;27(2):262-268.

77. Ide K, Yamada H, Takuma N, et al. Green tea consumption affects cognitive dysfunction in the elderly: a pilot study. Nutrients. 2014;6(10): 4032-4042.

78. Yokogoshi H. Green tea and brain function. In: Isemura M, editor. Health Benefits of Green Tea. 2013. Available from: http://dfns.u-shizuoka-ken. ac.jp/labs/tsc/.

79. Yoto A, Murao S, Motoki M, et al. Oral intake of $\gamma$-aminobutyric acid affects mood and activities of central nervous system during stressed condition induced by mental tasks. Amino Acids. 2012;43(3):1331-1337.
80. Okello EJ, Abadi AM, Abadi SA. Effects of green and black tea consumption on brain wave activities in healthy volunteers as measured by a simplified Electroencephalogram (EEG): a feasibility study. Nutr Neurosci. Epub 2015 Feb 25.

81. Mazzanti G, Di Sotto A, Vitalone A. Hepatotoxicity of green tea: an update. Arch Toxicol. 2015;89(8):1175-1191.

82. Patel SS, Beer S, Kearney DL, Phillips G, Carter BA. Green tea extract: a potential cause of acute liver failure. World J Gastroenterol. 2013;19(31):5174-5177.

83. US Department of Health and Human Services. National Institutes of Health. US National Library of Medicine. Green tea (Camellia sinesis). Available from: http://livertox.nlm.nih.gov/GreenTea.htm. Accessed September 24, 2015.

84. Shirai T, Reshad K, Yoshitomi A, Chida K, Nakamura H, Taniguchi M. Green tea-induced asthma: relationship between immunological reactivity, specific and non-specific bronchial responsiveness. Clin Exp Allergy. 2003;33(9):1252-1255.

85. Otera H, Tada K, Sakurai T, Hashimoto K, Ikeda A. Hypersensitivity pneumonitis associated with inhalation of catechin-rich green tea extracts. Respiration. 2011;82(4):388-392.

86. Chen D, Wan SB, Yang H, Yuan J, Chan TH, Dou QP. EGCG, green tea polyphenols and their synthetic analogs and prodrugs for human cancer prevention and treatment. Adv Clin Chem. 2011;53:155-177.

87. Saito E, Inoue M, Sawada; for NJPHC Study Group. Association of green tea consumption with mortality due to all causes and major causes of death in a Japanese population: the Japan Public Health Centerbased Prospective Study (JPHC Study). Ann Epidemiol. 2015;25(7): $512-518$.

\section{Publish your work in this journal}

Botanics: Targets and Therapy is an international, peer-reviewed, open access journal focusing on the discovery and development of active compounds based upon or found naturally occurring in the plant kingdom that may have therapeutic potential in any disease state. The manuscript management system is completely online and includes a very

\section{Dovepress}

quick and fair peer-review system. Visit http://www.dovepress.com testimonials.php to read real quotes from published authors. 